The Demand for Health Insurance among Uninsured Americans: Results of a Survey Experiment and Implications for Policy

by

Alan B. Krueger, Princeton University Ilyana Kuziemko, Princeton University

CEPS Working Paper No. 217

April 2011 


\title{
The Demand for Health Insurance among Uninsured Americans: Results of a Survey Experiment and Implications for Policy*
}

\author{
Alan B. Krueger \\ Princeton
}

\author{
Ilyana Kuziemko
}

Princeton and NBER

April 13, 2011

\begin{abstract}
Most existing work on the price elasticity of demand for health insurance focuses on employees' decisions to enroll in employer-provided plans. Yet any attempt to achieve universal coverage must focus on the uninsured, the vast majority of whom are not offered employer-sponsored insurance. In the summer of 2008, we conducted a survey experiment to assess the willingness to pay for a health plan among a large sample of uninsured Americans. The experiment yields price elasticities substantially greater than those found in most previous studies. We use these results to estimate coverage expansion under the Affordable Care Act, with and without an individual mandate. We estimate that 39 million uninsured individuals would gain coverage and find limited evidence of adverse selection.
\end{abstract}

\footnotetext{
${ }^{*}$ We thank Jim Harter and Nicholas Arture of the Gallup Organization for help administering our survey questions, the Industrial Relations Section at Princeton for financial support, and David Cutler, Amy Finkelstein, Leemore Dafny, Sherry Glied, Jon Gruber, Seema Jayachandran, Uwe Reinhardt and participants at the Princeton Center for Health and Wellbeing for helpful comments. Alan Krueger is a senior scientist at Gallup. Contact information: akrueger@princeton.edu; kuziemko@princeton.edu
} 


\section{Introduction}

Expanding coverage to the roughly 50 million Americans who lack health insurance has long been a key public policy concern, and one that has received enormous attention in recent years. ${ }^{1}$ Most notably, the Affordable Care Act of 2010 (ACA) attempts to cover these individuals via a combination of a large expansion of Medicaid and subsidies to purchase private insurance on state-run health insurance exchanges. ${ }^{2}$

Relying on existing research to predict the effects of such a fundamental reform on the currently uninsured is problematic, because existing work generally focuses on the decision to enroll in employer-sponsored health insurance. Of course, there is a good reason for this focus: employers are, after all, the source of insurance for a majority of the non-elderly population. However, the currently uninsured are rarely offered the opportunity to purchase insurance through an employer (Kaiser Family Foundation, 2004), calling into question the utility of existing estimates for understanding insurance demand of this population. Not only are these individuals substantially poorer than the average worker offered employer insurance, but the decision to, say, purchase subsidized insurance from a state exchange might fundamentally differ from the decision to enroll in an employer-sponsored health plan, which takes place in the context of co-workers, an employer and potentially benefits counselors. The same questions of generalizability arise for existing work on adverse selection, most of which relies on employee take-up decisions.

To address these concerns, we devised survey questions specifically designed to elicit the expressed willingness to pay among the uninsured for a comprehensive health plan. Existing data on the uninsured are generally limited in part because many respondents must be screened in order to yield a sample of uninsured people large enough to generate precise estimates, given that over 80 percent of Americans are covered by some form of

\footnotetext{
${ }^{1}$ See http://www. census.gov/prod/2010pubs/p60-238.pdf for the most recent estimates of the number of uninsured Americans.

${ }^{2}$ The Kaiser Family Foundation summarizes the Act at http://www.kff .org/healthreform/ upload/8061.pdf.
} 
health insurance. Fortunately, for a two-week period during the summer of 2008, the Gallup Poll included our questions in their ongoing survey of 1,000 individuals a day. We asked respondents whether they would purchase a comprehensive health plan for a given monthly premium, and then lowered the price in several stages for those who initially said they would not purchase it. To the best of our knowledge, our dataset is the first to elicit self-reported willingness-to-pay for health insurance among a large sample of uninsured Americans.

Our results suggest that subsidizing the purchase of insurance plans would significantly reduce the population of the uninsured. For example, we estimate that about sixty percent of the uninsured would voluntarily enroll for an annual premium of $\$ 2,000$. Under the current specification of subsidies in the ACA, we estimate that over 75 percent of uninsured adults would enroll, implying that some 39 million uninsured individuals would gain coverage as a result of the law. We also estimate that stripping the individual mandate from the law - the constitutionality of which is being challenged in federal court-would lead to between 7 and 12 million fewer individuals gaining coverage.

The Gallup data included extensive information on health status, and thus allow us to gauge the extent of adverse selection for a given subsidy schedule. We find, consistent with past literature, that less healthy individuals have lower price elasticities. ${ }^{3}$ However, when we calculate the prices individuals would actually face under the ACA subsidy schedule, we find no evidence that less healthy individuals would be more likely to enroll, with or without a mandate. As enrollment is a function of both elasticities and the price points individuals face, we caution that other subsidy schedules may well lead to adverse selection, and indeed Chandra et al. (2011) find that the individual mandate was important in limiting adverse selection under Massachusetts' 2006 health reform, which, as we discuss, mirrors the ACA is important respects. With or without a mandate, we find no evidence that those predicted to take-up private insurance are less healthy than those who are already privately insured, suggesting premiums for the latter group should not increase due to a change in

\footnotetext{
${ }^{3}$ See, for example, Strombom et al. (2002), who find that older and sicker individuals appear less sensitive to premium price in their decisions among different health plans.
} 
the composition of the private insurance pool.

We calculate elasticities of take-up with respect to premium price of around one, significantly larger than those from past work. There are several possible explanations for this difference. First, as mentioned earlier, almost all past work is based on individuals' decisions to join employer-provided health plans. Moreover, past studies generally suffer from: (1) the need to impute prices for those who do not have health insurance or cannot recall their premium price; (2) the existence of a wide variety of health plans with different features rather than a homogeneous plan.

Our sampling frame allows us to gather a large group of uninsured individuals in order to directly elicit their willingness to pay for health insurance. Moreover, our survey design allows us to focus on a specific insurance product and to vary its price exogenously. Overall, our results suggest that applying the elasticities in past work may seriously under-estimate the effect of policies to extend coverage to the uninsured. Indeed, we estimate higher take-up rates under the provisions of the ACA than does the Congressional Budget Office.

Of course, using survey data on people's self-reported decisions in hypothetical situations presents serious concerns, such as anchoring bias (the tendency of individuals to choose a valuation close to the first price the survey suggests). We make an effort to address these concerns by randomly varying the initial prices we offer respondents and find no significant effect of the initial offer on respondents' final valuation. Moreover, our survey differs from contingent valuation studies, which typically ask respondents to value a public good, such as an environmental project, with which they have little personal experience. We instead ask about a private good that most people would have experience with: given the well-documented "churning" in health-insurance status (see, e.g., Klein et al. 2005), many uninsured individuals would have been insured in the recent past. However, other potential biases related to hypothetical valuation are more difficult to address and we later discuss how they might affect our estimates.

The remainder of the paper is organized as follows. Section 2 reviews past work on the 
price elasticity of health insurance. Section 3 describes the Gallup Daily Poll as well as the questions we added to it. Section 4 presents data analysis on uninsured individuals' decisions to buy into a subsidized health plan, estimating aggregate price elasticities, predicting individual reservation prices, and testing for the presence of adverse selection. Section 5 uses the results in the previous sections to estimate the effects of the Affordable Care Act. Section 6 offers concluding remarks.

\section{Review of Related Literature}

At least three strands of research speak to the potential effects of subsidizing the purchase of health insurance for the uninsured. First, many papers have attempted to estimate the price elasticity of health insurance demand, with the majority of work focusing on employees' decisions to join health plans offered by their employers. Second, other papers have examined take-up rates among those eligible for past expansions of government health programs such as Medicaid. Finally, we review the experience in Massachusetts, which in 2006 implemented a health insurance reform very similar to the Affordable Care Act.

\subsection{Estimating the price elasticity of health insurance demand}

In general, existing work examines either firm-level data and estimates the share of workers who take up insurance as a function of the premium prices of the plans a firm offers, or individual-level data and estimates take-up decisions as a function of reported or imputed premium prices. Papers in this area typically face several common challenges in estimating the price elasticity of demand for this population.

First, noisy price imputation will lead to measurement error, generally biasing elasticity estimates toward zero. This concern is especially acute with individual-level data, as those who chose not to enroll in a health plan are unlikely to perfectly remember the premium price they were offered. Second, elasticity estimates implicitly assume a homogenous insurance product, when in fact individuals that pay higher premiums may be obtaining more generous health care benefits, again biasing elasticities toward zero. 
Even if researchers are able to surmount these challenges, applying their results to the population of uninsured individuals is problematic. Most studies analyze the decision of employees to take-up health plans provided by their employers, and thus it is unclear how these elasticities relate to the uninsured population, of whom less then fifteen percent have access to employer-provided insurance. ${ }^{4}$

Some key papers have sought to address these problems. In a firm-level analysis, Cutler (2003) estimates the share of workers who take-up employer-provided insurance as a function of premium price. He uses the price of the cheapest plan offered, arguing that doing so lessens worries about the premium price being a direct function of employee decisions (relative to, say, using the average price of the plans employees chose). He finds elasticities ranging from -0.03 to -0.1, similar to results in Chernew et al. (1997) and Blumberg et al. (2001).

Gruber and Washington (2005) use the introduction of pre-tax payment of premiums for postal workers (and, later, all federal workers) as a source of plausibly exogenous variation in effective premium price. They find almost no effect of price on take-up (an implied elasticity of -0.007) but substantial evidence that the subsidy led employees to choose more expensive plans. They note that expanding coverage was never the goal of the policy change (the hope was to make federal jobs more competitive with those in the public sector). Thus, knowledge of the effective price change among uninsured federal workers may have been limited.

Gruber and Poterba (1994) examine the Tax Reform Act of 1986, which for the first time allowed the self-employed to deduct the cost of their health-insurance premiums. As the benefit of a deduction depends on an individual's federal income tax rate, the reform

\footnotetext{
${ }^{4}$ In our data, 65 percent of the uninsured are employed (see Table 1). According to Kaiser Family Foundation (2004), among uninsured workers, only twenty percent were offered employer insurance and turned it down, with another twenty percent working in firms that offer insurance to some workers but are themselves ineligible and the rest working in firms that do not offer insurance at all). We thus estimate that $0.65 * .20=13$ percent of uninsured adults in our sample turned down an offer of employer insurance.
} 
generated differential effective price changes among the self-employed. Their difference-indifference estimation suggests an elasticity of about -1.8. Their study is especially relevant for two reasons. First, the authors estimate far greater elasticities than papers examining employee take-up of employer-provided plans. Second, the self-employed may be a good analogue for the uninsured in that both groups would make their health insurance decisions largely independent from the influence of employers or fellow employees. However, the preferences, constraints, and resources of the uninsured may not mirror those of the selfemployed.

\subsection{Medicaid take-up literature}

A second set of papers examines why take-up rates of free government health insurance have been so low. Currie and Gruber (1996) study the expansion of Medicaid coverage in the 1980s and 1990s and find that only about a third of pregnant women eligible for Medicaid actually enroll. Card and Shore-Sheppard (2004), exploiting sharp age cut-offs that determined eligibility under the Medicaid expansions, find even lower rates of take-up.

Low take-up rates among those eligible for Medicaid (which requires no out-of-pocket costs and offers more generous benefits than almost any employer plan) suggests a very

limited capacity of even a heavily subsidized plan to extend coverage to the uninsured. However, there are a number of reasons why these estimates may not predict enrollment rates in a setting such as the $\mathrm{ACA}$.

First, the results themselves may be underestimates of the true Medicaid take-up rate as researchers may have only noisy proxies for true Medicaid eligibility. As Remler and Glied (2003) note, programs with asset tests often appear to have low take-up rates in part because individuals who appear eligible to the researcher - who often only has data on individuals' income levels - are not in fact eligible. While many states have recently ended Medicaid asset tests for children, most have kept them in place for parents and other adults (Kaiser Family Foundation, 2009), which may explain the apparent low take-up rates of adults documented by Sommers and Epstein (2010) and others. Daponte et al. 
(1999) find that proxying eligibility with whether an individual meets the income test substantially decreases estimated take-up rates in the food stamp program: only about half of a sample of poor households whose income made them eligible for the program met the other requirements in the state of Pennsylvania.

Second, many people covered by the Medicaid expansions studied in the past literature already had other sources of coverage. Currie and Gruber estimate that 66 percent of individuals made eligible between 1987 and 1992 already had private insurance. Although Medicaid is free, there is significant paperwork associated with proving eligibility and some doctors are reluctant to treat Medicaid patients because of lower reimbursement rates. Thus, privately insured individuals may be hesitant to switch despite the potential cost savings. In order to address the problem that pre-existing private insurance coverage would mask the true demand for a government-subsidized insurance product, we estimate price elasticities on a large sample of uninsured individuals.

Finally, many individuals may not understand their Medicaid eligibility. Indeed, current Medicaid eligibility rules are quite complicated: they vary by state, and within state usually vary depending on age and household composition. Aizer (2007) finds that informational barriers are an important reason for low take-up rates, especially among Hispanics and Asians. The implementation of a national reform with uniform subsidies might overcome some of these barriers. Notably, the ACA eliminates asset tests for Medicaid and makes eligibility a function only of income. Moreover, a plan with an individual mandate could encourage individuals to learn all their insurance options once they discover they otherwise must pay a financial penalty.

\subsection{Take-up of subsidized insurance by the uninsured in Massachusetts}

Perhaps a more direct way of estimating take-up of subsidized insurance at the national level is to examine the experience of Massachusetts, which in 2006 implemented a health reform very similar to the ACA. Estimates of take-up vary somewhat, but all suggest that reform has essentially eliminated uninsurance in the state. 
The state itself reports that the uninsured share of non-elderly adults - the population represented our Gallup sample - fell from thirteen to four percent in the first two years of the reform. The Kaiser Family Foundation reports that in the first three years two-thirds of the total uninsured population gained insurance. The state's most current estimates indicate that only 2.7 percent of residents remained uninsured in 2009, even in the midst of the severe recession. ${ }^{5}$

While the 2006 Massachusetts reform and the Affordable Care Act are similar, Massachusetts is not representative of the country as a whole in important respects. Notably, the year before the reform, only two states (Minnesota and Wisconsin) had a lower percentage of uninsured residents. Similarly, in 2009, only seven states had higher median household income and no state had a higher share of its residents with at least a bachelors degree. ${ }^{6}$ For these reasons, while Massachusetts serves as an important benchmark, we focus on gathering data on a nationally representative sample of uninsured Americans.

\section{Data}

\subsection{The Gallup-Healthways Daily Poll}

Every day since January 2008, the Gallup Organization has surveyed about 1,000 individuals age 18 and older as part of the Gallup-Healthways Daily Poll. The interview takes about 15 minutes, with questions ranging from respondents' preferences in upcoming elections to their credit history, as well as basic demographic information. Fortunately for our purposes, the survey includes a number of questions on individuals' health conditions, health behaviors and health insurance coverage. ${ }^{7}$

\footnotetext{
${ }^{5}$ See "Facts and Figures" at https://www.mahealthconnector.org/portal/site/ connector/menuitem.d7b34e88a23468a2dbef6f47d7468a0c?fiShown=default for estimates from the Massachusetts Health Connector, the independent state agency charged with helping residents comply with the law. Kaiser offers a summary of the state law and its affects so far on the uninsurance rate at http://www.kff.org/uninsured/upload/7777-02.pdf.

${ }^{6}$ See http://www. census.gov/compendia/statab/2011/tables/11s0229.xls.

${ }^{7} \mathrm{~A}$ list of the core questions is available at www.well-beingindex.com/ methodology-questions.html.
} 
Gallup takes several steps to draw a representative sample of the population: they use dual-frame random-digit-dial sampling that includes cell phones; they follow a random selection method to choose one respondent within a household; and they provide Spanishlanguage interviewers for respondents who speak only Spanish. Gallup also provides sample weights to compensate for disproportionalities in selection probabilities and non-response, so that the weighted sample matches the national distribution in terms of age, sex, region, gender, education and race. We utilize the sample weights in all of our analyses.

\subsection{Our additions to the Gallup Survey}

Gallup agreed to add to its daily survey several questions we specifically designed to elicit uninsured individuals' willingness to pay for a subsidized private plan. From August 22 to September 8, 2008, Gallup asked everyone who reported being uninsured (1,332 individuals) our questions, which took the following general form: "If you could get a health insurance policy for yourself that is as good as the one that members of Congress have, given your current financial situation, would you buy it for $\$ X$ a year, which works out to $\$ X / 12$ per month?" 8 As we explain in more detail below, the cost $X$ varied. We randomly assigned individuals to different starting values of $\$ X$ and then lowered $\$ X$ if the respondent said he or she would not purchase the plan.

One concern with data on hypothetical choices is anchoring bias, the tendency of subjects to insufficiently adjust their response from an arbitrary starting point (Tversky and Kahneman, 1974). For example, anchoring bias would arise if subjects in our survey claimed they would purchase health insurance at or near the first price suggested because they inter-

\footnotetext{
${ }^{8}$ The phrase "as good as members of Congress receive" was meant to signal the comprehensiveness of the health plan in question. Indeed, the Affordable Care Act creates state exchanges modeled after the Federal Employee Health Benefits Plan, which covers members of Congress. Interviewers were provided the following instructions: "If respondent asks what the health insurance plan is like for members of Congress, read:) Members of Congress can choose from a variety of health insurance plans. A common choice is Blue Cross/Blue Shield. This insurance requires co-pays and deductibles similar to those paid by many private sector workers. For example, a primary doctor visit requires a $\$ 20$ co-pay; a day in the hospital requires a $\$ 100$ deductible; participants can see a doctor in the preferred provider network; some dental coverage is provided, but vision care is not covered."
} 
pret it as signaling the social desirability of health insurance. Alternatively, some subjects might reject the first price but upon hearing a second, lower price, accept it so as not to appear stubborn to the interviewer, even though they privately judge both prices as too high.

To assess the importance of this problem, we randomly assigned the uninsured subjects to one of two questionnaires. Questionnaire A started with an annual premium price of $\$ 4,000$ and then lowered the price first to $\$ 3,000$ for those who said no, and then to $\$ 2,000$ if respondents said no to $\$ 3,000$ (though subjects were not told that lower prices would follow). Questionnaire B started with a price of $\$ 3,000$ and then followed with a price of $\$ 2,000$. Comparing responses across the two questionnaires allows us to test for anchoring bias, and we report results of these tests in the next section. ${ }^{9}$

\section{Results from the Gallup survey}

\subsection{Raw survey results}

Table 1 presents summary statistics separately for the insured and uninsured subjects in the sample Gallup collected during our 16-day window (we restrict the sample to individuals under 65 as this older group is eligible for Medicare). Though we focus on the uninsured in most of the later analysis, it is useful to consider how these two groups differ across a variety of measures. In general, the uninsured in our data are younger, more likely to be male and less likely to be married, consistent with past survey data (see, e.g., Cheong et al. 2007). Their income is less than half that of the insured, and they are less likely to have a job. Notably, the uninsured are more than twice as likely as the insured to have ever been denied coverage when trying to purchase health insurance in the past.

Figure 1 shows the share of respondents who say they would enroll in the plan at each

\footnotetext{
${ }^{9}$ Gallup randomized within each day of the survey and the randomization appears to have been successful. The differences between individuals assigned questionnaire A versus B in the share female, Black, Hispanic, employed, ever denied health care and the mean age, income and BMI are all insignificant at the ten percent level, both individually and jointly. Results available upon request.
} 
price, plotted separately by which questionnaire they answered. Of those randomly assigned to Questionnaire A, 26.9 percent said they would purchase the plan if the annual premium were $\$ 4,000$ and an additional 11.9 percent said they would once the price was lowered to $\$ 3,000$, for a total of 37.9 percent. This share is similar to the 34.6 percent of Questionnaire B respondents who agreed to purchase the plan at $\$ 3,000$, even though in their case $\$ 3,000$ was the first price presented to them. The two groups diverge more when facing a price of $\$ 2,000$, with a take-up rate of 59.5 percent for Questionnaire A respondents and 51.7 percent for Questionnaire B. Overall, however, anchoring bias appears minimal. We more rigorously test for anchoring bias in the regression analysis. ${ }^{10}$

We calculate arc elasticities between each pair of (take-up,price) points in Figure 1 by dividing the percent change in take-up by the percent change in price, where each change is calculated relative to its mid-point. To avoid cluttering the figure, we generally focus on those elasticities based on price variation within the same survey treatment as opposed to comparing across surveys, though include all other elasticities in the notes to the table.

The five take-up rates generate eight arc elasticities, all clustered closely around 1.0, and far larger than those found in most past work. Of particular interest is the elasticity estimate based on the take-up rate at $\$ 4,000$ from Questionnaire A and $\$ 3,000$ from Questionnaire B, the first prices presented by each of the surveys. If anchoring bias were driving individuals' responses, then this comparison should yield minimal differences in take-up and thus a substantially reduced elasticity, but the resulting elasticity of 0.87 is only slightly below the elasticities generated from within-questionnaire price variation.

\footnotetext{
${ }^{10}$ Our finding of minimal anchoring bias differs from contingent valuation studies, in which respondents are surveyed about their valuation of public, non-market goods (see Green et al. 1998 for evidence of anchoring bias in contingent valuation surveys). One possible explanation is that our results are more robust because we asked people to report how they would make decisions concerning private goods they probably have considered purchasing before, not how much they would be willing to contribute to support public goods, a decision that they do not encounter in their everyday lives. Brown et al. (2008) find that individuals are most consistent and reliable (i.e., they do not make choices that imply $A>B>C>A$ and that they make the same choice when the same choice set is presented to them at different points during the experiments) when they are deciding between a private good and a sum of money (the case in our experiment), as opposed to two private goods or a public good and money.
} 


\subsection{Regression results}

The Gallup data allow us to estimate the following equation:

$$
\text { Takeup }_{i j}=\beta \text { Price }_{i j}+\gamma X_{i}+\varepsilon_{i j}
$$

where individuals are indexed by $i$, prices by $j$, Takeup $_{i j}$ is an indicator variable for whether individual $i$ says she would purchase the health plan at price $j$, Price $_{i j}$ is the premium price (rescaled so that its coefficient represents the percentage-point change in take-up associated with a $\$ 1000$ increase in premium price), $X_{i}$ is a vector of individual characteristics, and $\varepsilon_{i j}$ is an error term. We cluster standard errors at the individual level to account for the fact that each individual has two (Questionnaire B) or three (Questionnaire A) price observations. We down-weight the latter group so that individuals are not given greater weight merely because they were randomized into Questionnaire A (though this re-weighting leaves the results essentially unchanged). ${ }^{11}$

Col. (1) of Table 2 shows the results from an OLS estimation of this equation without covariates. The coefficient equals -0.152 , consistent with the roughly 30-percentage-point drop in take-up between $\$ 2,000$ to $\$ 4,000$ depicted in Figure 1. Cols. (2) and (3) show that the result is robust to including basic controls - col. (3) includes these controls and col. (2) re-estimates the col. (1) specification on the col. (3) sample. These results suggest that price is uncorrelated with our control variables, as would be expected under random assignment.

Cols. (4) and (5) show that the coefficient estimate is robust to using a probit specification or adding individual fixed effects, respectively. Finally, we examine whether including multiple price observations for each person leads to incorrect inference. While clustering at the person level should in principle adjust standard errors correctly, we take a more conservative approach by randomly choosing one price observation per person and then es-

\footnotetext{
${ }^{11}$ As noted earlier, all results employ Gallup's sample weights. As such, for these regressions, the weights are merely scaled by two-thirds for individuals in Questionnaire A.
} 
timating equation $(1)$ on this smaller $(n=1,184)$ sample. Repeating this estimation 1000 times yields a mean coefficient value of -0.151 with a standard error of 0.021 (implying a $t$-statistic greater than seven). Therefore, even after throwing out a significant amount of information we find highly precise point estimates.

Some of the covariates reported in Table 2 are worth noting. Blacks are more likely to say they would purchase the plan. So are higher-income individuals, not surprising given that price is in absolute dollars as opposed to a share of individual income. Notably, the dummy variable indicating that the subject answered Questionnaire A (which initially offers the chance to purchase the plan at $\$ 4,000)$ is positive. This result is not surprising given that in Figure 1 take-up rates for Questionnaire A are everywhere to the left of those for Questionnaire B. However, the coefficient does not approach statistical significance $(p$-value $>0.6)$ and is small in magnitude, suggesting limited anchoring bias.

In Table 3, we report elasticities for several subsamples, based on the fixed-effects specification in col (5) of Table 2. The first row shows an elasticity for the entire sample around -1.07, consistent with the arc elasticities in Figure 1. Elasticities across race, gender, and employment and marital status are quite similar. Older and sicker (as measured by selfreported health problems and past attempts to purchase insurance) individuals are less price elastic as are relatively higher-income individuals. The health-status and age results are consistent with Strombom et al. (2002), and are consistent with this group being uninsured not because they have little demand for insurance but because their health costs mean they are not offered coverage at an affordable price.

\subsection{Estimating the demand curve for insurance among the uninsured}

The raw data give us an interval (though not always a closed interval) for each person's reservation price, but we can improve on the accuracy of the reservation price by estimating an interval regression that conditions on a large set of covaraiates: specifically, all the controls listed in Table 2, as well as a set of ten income dummies, interactions between sex and race, and dummy variables related to marriage and cohabitation arrangements. 
This regression gives us a vector of estimated coefficients with which we can predict each person's valuation of the insurance product. So as not to discard any information from the survey, we use the estimates to calculate the expected valuation conditional on it being in the respondents reported interval.

More formally, we take the coefficient vector $\hat{\beta}$ from the interval regression. Then, for each person $i$ we take their chosen interval $\left(a_{i}, b_{i}\right)$ and calculate $\mathbb{E}\left(\hat{\beta} X_{i}+\varepsilon_{i} \mid a_{i}<\hat{\beta} a X_{i}+\varepsilon_{i}<\right.$ $\left.b_{i}\right)$. As the interval need not be closed, $b_{i}$ can equal $-\infty$ or $\infty$ and the expectation can in fact be negative, though for less than two percent of observations do we estimate negative reservation prices. ${ }^{12}$

Figure 2 shows the demand curve generated from this simple algorithm. We plot price on the $y$-axis and the share of individuals whose valuation of the health plan is at least that price on the $x$-axis. Not surprisingly, given that we constrain predictions to be in the respondent's reported interval, the demand curve roughly takes the shape of a step function, with large discontinuities around the endpoints of the survey intervals.

\subsection{Discussion}

Overall, the results in this section suggest a precisely estimated effect of price on take-up rates substantially greater than that found in past work. There are a number of potential explanations for this discrepancy.

First, our sample is markedly different from those used in most existing papers on health insurance decisions, which focus on the decision to take-up employer-provided insurance. As we noted earlier, less than fifteen percent of the uninsured have access to employer-provided insurance. Furthermore, most studies use samples in which the majority of respondents are actually covered by insurance and as insured people are far wealthier (see Table 1), we thus focus on poorer individuals than past work has, who may exhibit different elasticities.

In our sample, lower-income adults are indeed more price elastic. As seen in Table 3, the

\footnotetext{
${ }^{12}$ Results are unchanged if we simply take the prediction $\hat{\beta} X_{i}$, keep it if $\hat{\beta} X_{i} \in\left(a_{i}, b_{i}\right)$ and otherwise replace it with the endpoint of person $i$ 's interval that is closest to $\hat{\beta} X_{i}$.
} 
richest 25 percent of people in our sample have elasticities roughly half the magnitude of the rest of the sample, suggesting that elasticities diminish with income even in our relatively low-income sample. Thus differences in income could account for part of the reason we find much larger elasticities than do past researchers.

Second, even if respondents to our survey have the same demand function for health insurance as do subjects in past studies, given that we are focusing on variation around a substantially subsidized premium price, we are estimating the elasticity at a lower price point than most papers. There is no theoretical reason to expect that insurance demand functions exhibit a constant elasticity with respect to price, and thus no reason to expect our elasticity estimates to be the same as those measured around a higher price point.

Third, perhaps most obviously, our methodology differs from past work, as we rely on respondents' answers regarding hypothetical purchases. On the one hand, if people want to sound agreeable in surveys and thus tend to say they would purchase the plan at the first price we offer, then elasticities would be biased toward zero. On the other hand, a heuristic such as "always say no to the first price but yes to the second" would likely lead to elasticities that were upwardly biased in magnitude. This bias story is somewhat undermined by the elasticity estimate of 0.87 (labeled in Figure 1) based on the first price of each survey$\$ 4,000$ in Questionnaire A and $\$ 3,000$ in Questionnaire B - as respondents in both cases have not already refused the product at a higher price. However, we certainly cannot claim that the survey design addresses every possible criticism related to the hypothetical nature of our subjects' valuations.

\section{Policy simulations}

We close the paper by using the results in the previous section to simulate the effects of different subsidy and penalty schedules, focusing in particular on the Affordable Care Act, with and without the individual mandate. We estimate enrollment effects, investigate differential take-up by health status, and compare the health among those predicted to take- 
up private insurance via the ACA subsidies to those who already have private insurance. For simplicity, we generally assume that ACA coverage provisions have their full effect in 2014, the first year they are implemented. In practice, however, the full effect might not be realized until health insurance plans, government regulators and individuals have had a year or two of experience with the new system.

One potential drawback of our data set is that it was collected nearly six years before the Affordable Care Act's central coverage expansions. For several reasons, however, we believe data from this period may be more useful in projecting take-up rates under the ACA than data collected today.

First, the employment landscape at the time of our survey is similar to projections for 2014. The unemployment rate in August and September of 2008 was 6.1 and 6.2 percent, respectively. The CBO projects the unemployment rate to be 6.6 percent in 2013 - the year enrollment decisions would be made - and 5.0 in 2014, the year the insurance exchanges open for business. Collecting data today would entail extrapolating from an environment of historically high unemployment.

Second, we collected our data more than 18 months before the passage of the ACA (George W. Bush was still president), long before the political fervor over health reform and "Obamacare" began. Again, one might worry that collecting data today would reflect respondents' passion either for or against the bill, instead of reflecting their actual willingness to pay for a specific insurance contract.

\subsection{Estimating take-up rates under the Affordable Care Act}

\subsubsection{Enrollment without a penalty}

Estimating the subsidized premium price for households under the ACA is relatively straightforward with the Gallup data. Using household size and yearly household income, we calculate each individuals' household income relative to the poverty line. ${ }^{13}$ Beginning in 2014,

\footnotetext{
${ }^{13}$ Household size is not actually included in the Gallup survey. We impute household size by summing the total number of children in the household (which is asked) and two for individuals
} 
Medicaid will cover individuals with income below 133 percent of the poverty line, so we set their premiums equal to zero. Between 133 and 400 percent of the poverty line, we follow the subsidy schedule established in the ACA - subsidized premium prices increase continuously from 2.8 percent of household income for those at 133 percent of the poverty line to 9.8 percent of income for those at 300 percent of the poverty line. The price remains at 9.8 percent of income between 300 and 400 percent of the poverty line. As 85 percent of individuals in our uninsured sample are below 400 percent of the poverty line, these two provisions cover the vast majority of cases.

Above 400 percent of the poverty line, individuals do not receive subsidies. Since the question we formulated refers to individual (as opposed to family) insurance, we assume such individuals would face a price of $\$ 3756.96$, the price of the basic Blue Cross plan offered to federal employees in 2008. Note that this price is the total of the employee and employer contribution and as such substantially over-states the price for anyone with an offer of employer insurance - for example, the federal worker would only pay $\$ 1023.84$ a year for the Blue Cross plan, with his employer (the federal government) covering the rest of the premium. Using the household component of the 2005-2006 Medical Expenditure Panel Survey, we estimate that over two-thirds of uninsured adults ages 18-64 living in households with income over 400 percent of the poverty line have an offer of insurance from their or their spouse's employer, and as such we believe the premium we set for such individuals in our sample is likely too high, leading to under-estimated enrollment results. ${ }^{14}$

In our baseline estimate, we assume anyone whose estimated willingness-to-pay is above their premium price takes-up coverage, and report these estimates in the first row of Table 4. Col. (1) reports that 64 percent of currently uninsured individuals would gain coverage. who report being married or living with a domestic partner and one otherwise.

${ }^{14}$ We caution that the MEPS sample has just over 150 uninsured adults above 400 percent of the poverty line between ages 18 and 64, so our estimates on employer offering are likely noisy. Moreover, these individuals may disproportionately work for firms that only cover a relatively small portion of the premium, thus leading them to refuse the offer. Nevertheless, assuming that individuals in our sample above 400 percent of the poverty line must pay both the employee and employer side of the premium surely overstates their actual financial contribution. 
Col. (2) translates this figure into an estimated number of covered adults. The CBO projects that without the ACA, 51 million non-elderly individuals would be without insurance in 2014. Assuming that the adult share of that population remains at its 2009 level of 0.839 , we estimate that $0.839 * 51$ million $* 0.643=28$ million adults would enroll in either Medicaid or an exchange insurance plan in $2014 .{ }^{15}$ Assuming an equal share of children would gain coverage, we estimate that 33 million people would gain coverage via the ACA provisions without a mandate.

Given that we estimate negative reservation prices for less than two percent of individuals in our sample and that Medicaid has no premium, the calculation in the first row of Table 4 essentially assumes full Medicaid take-up. Given that individuals below 133 percent of poverty will be de facto insured whether or not they officially enroll in Medicaid, in terms of who gains access to coverage, this assumption seems reasonable. From a fiscal standpoint, even if Medicaid recipients do not enroll until they are ill, they are not "free-riding" as they do not pay a premium regardless of when they choose to enroll.

Nevertheless, officially enrolling in Medicaid may facilitate contact with health care providers and thus promote preventive and primary care. And official estimates of insurance coverage may depend on whether Medicaid eligibles actually enroll. Thus, we present estimates assuming different levels of Medicaid take-up in the second and third rows of Table 4. In the second row we assume that 85 percent of Medicaid-eligible individuals enroll, which lowers the total take-up rate among all uninsured adults from 64 to 62 percent. Using the same methodology as before, this take-up translates to 26 million adults or 31 million individuals gaining coverage. In the third row we assume that only fifty percent of Medicaid-eligibles take up coverage, and the corresponding numbers are 20 and 24 million.

The fourth row of the table focuses on those individuals above 133 percent of the poverty line and thus ineligible for Medicaid. These individuals would gain coverage via the private insurers in the state exchanges. We estimate that without a mandate just under half of

\footnotetext{
${ }^{15}$ The 51 million figure is taken from the CBO's cost estimate of the final version of the ACA: http://www.cbo.gov/ftpdocs/113xx/doc11379/AmendReconProp.pdf.
} 
the uninsured above 133 percent of the poverty line, or roughly 12 million people, would voluntarily enroll in an exchange plan. ${ }^{16}$

\subsubsection{Enrollment with a penalty}

Following the typical terminology of the debate, we refer to an "individual mandate" as the financial penalty individuals must pay under ACA if they do not enroll in a health insurance plan. To assess the effect of the penalty, we add the penalty to individuals' estimated willingness to pay. The implicit assumption is that if individuals were willing to pay, say, $\$ 2,000$ for a health insurance plan, they would be willing to pay $\$ 2,800$ for a health insurance plan and the opportunity to avoid losing $\$ 800$.

The terms of the individual mandate under the Affordable Care Act are relatively simple, and thus calculating each respondent's penalty is straightforward. The mandate is phased in between 2014 and 2016; in 2016, individuals must pay the maximum of $\$ 695$ or 2.5 percent of household income, with $\$ 695$ indexed to a cost-of-living adjustment for subsequent years. We use the CBO's inflation projections to deflate the $\$ 695$ into 2008 dollars. The mandate exempts certain groups, including those below the federal income tax filing threshold (in 2008, \$8,025 for individuals and $\$ 16,050$ for couples) and those facing a premium greater than eight percent of household income. We thus assume non-mandate take-up rates for these groups.

The last three columns of Table 4 present enrollment estimates assuming non-exempt individuals without insurance would be subject to the individual mandate penalty. Overall, we estimate that 77 percent of adults would enroll in a health plan assuming any Medicaideligible individual with positive willingness-to-pay enrolls, and the share falls to 76 and 72 percent if enrollment among mandate-exempt Medicaid eligibles falls to 85 and 50 percent, respectively. Note that in rows 2 and 3 under a mandate, we apply the Medicaid enrollment

\footnotetext{
${ }^{16}$ Note that many currently insured individuals would switch from their current plans to exchange plans, as only the latter qualify for subsidies, so that total enrollment in the exchanges would be substantially higher than the estimated number of uninsured individuals who would gain coverage via the exchanges.
} 
assumptions only to the exempt population (those under the filing threshold) as even many individuals at 100 percent of the poverty line would be subject to the $\$ 695$ penalty and thus would enroll in the free program to avoid it. Using the same method as before, these figures translate to between 37 and 39 million uninsured individuals enrolling in a health plan.

The last row shows that the mandate substantially increases private insurance take-up. The number of currently uninsured individuals estimated to enroll in an exchange plan increases by nearly forty percent when a mandate is added to the ACA subsidies.

\subsubsection{Discussion of enrollment estimates}

The effect of the mandate depends in part on how one views Medicaid take-up. Because more than half of those under 133 percent of the poverty level are nonetheless subject to the mandate because they are above the filing threshold, in many of our simulations the mandate substantially increases Medicaid take-up. If without a mandate we assume that only half of eligibles actually enroll, then a mandate increases total enrollment by over fifty percent. If one instead takes the view that eligibility for Medicaid is equivalent to being covered, then the mandate's effect is more limited.

Even when we assume low Medicaid take-up rates, our estimates are still greater than those of the CBO, likely reflecting the fact that our elasticity estimates are higher than those currently in the literature upon which the CBO bases its estimates. However, in at least one important aspect, our results may under-estimate actual take-up rates. Recall that we asked individuals what they would be willing to pay to "get a health insurance policy for yourself," whereas in reality the prices we imputed for individuals in Sections and were for policies that covered the entire household.

Our projections are very similar to findings from Massachusetts, which, as noted earlier, saw its uninsured rate for non-elderly adults fall by 70 percent after the adoption of the 2006 reform. Massachusetts might be a lower bound for the effect of the ACA for at least three reasons. First, as discussed earlier, the most recent data from Massachusetts likely reflect 
lower take-up rates due to the recession. Second, the individual mandate in Massachusetts does not apply to those below 150 percent of the poverty line, whereas the ACA mandate affects many households below the poverty line.

Finally, the initially low rate of uninsurance in Massachusetts may make it harder to substantially decrease the uninsured share if it is especially difficult to induce the last few percent of individuals to enroll, who might be the hardest for state agencies to reach. Long et al. (2010) use the American Community Survey to show that individuals who cannot speak English or live in households where no adult speaks English are among the most likely individuals to remain uninsured in Massachusetts. Similarly, other countries with "universal" health insurance often have one or two percent uninsured (see Kwon 2009 and Leu et al. 2009).

\subsection{Estimating adverse selection under the Affordable Care Act}

An important question is whether uninsured people with pre-existing conditions are, relative to other uninsured individuals, more likely to enroll relative to other currently uninsured individuals under the provisions of the Affordable Care Act. Differential take-up rates based on health status can generate adverse selection and unraveling of insurance markets (Rothschild and Stiglitz, 1976). There are many questions in the Gallup data referring to past and current health conditions, and we examine whether people who appear in worse health are more likely to say they would purchase health insurance in our pricing experiment.

\subsubsection{Results from simulating enrollment decisions}

The first panel of Table 5 reports differential enrollment patterns with respect to general health variables, using enrollment estimates from the first row of Table 4 . Without a mandate, no statistically significant differential selection patterns emerge for these variables. Of the two differences closest to being significant at the ten-percent level-older people and 
non-smokers being more likely to join - the first suggests those with higher medical costs would take-up coverage and the second those with lower costs. Similar effects obtain with a mandate, though the effect of age on the enrollment decision falls.

The next group of variables describe individual disease histories. Both with and without a mandate, individuals with a history of high blood pressure are more likely to take-up coverage. Without a mandate, those with a history of cancer are less likely to join whereas those with a history of asthma are more likely.

With and without a mandate, enrollment patterns display large differences along demographic dimensions, though the results above suggest these differences do not translate into large cost differences. Women and minorities are more likely to enroll, while higherincome individuals are less likely. The income result is likely due to two effects. First, subsidies, even on a percentage basis are more generous for poorer households. Second, richer households are more likely to have had the opportunity to purchase health insurance in the past but evidently chose not to. In other words, uninsured individuals who are in higher-income households will, all else equal, have a weaker preference for health insurance. This logic would suggest that women and minorities have had fewer past opportunities to purchase insurance, perhaps because they disproportionately work in firms that do not offer employer-sponsored insurance.

While Table 5 report take-up patterns for all currently uninsured respondents in the Gallup sample, we may worry more about adverse selection in the private market, given that individuals in Medicaid do not pay any premiums and thus cannot meaningfully "freeride." Appendix Table 1 replicates Table 5 after dropping all respondents under 133 percent of the poverty line and thus eligible for Medicaid. Most of the same patterns emerge, though fewer differences are statistically significant as the sample size shrinks.

\subsubsection{Discussion of adverse selection results}

How can our results of limited adverse selection be reconciled with past evidence of adverse selection in the health insurance market, most notably Cutler and Reber (1998)? First, 
while Cutler and Reber find that sicker people were more likely to choose a generous plan when offered a menu of choices, our results concern the extensive margin of choosing to have insurance at all. Second, our sample is poorer, with over thirty percent of respondents below the poverty line. As the ACA subsidies are highly progressive, those with the highest projected take-up rates have very low income levels and are most likely uninsured because they cannot afford to pay even a modest premium, not because they were denied on the basis of their health.

While we project minimal adverse selection under the specific ACA subsidy schedule, we do not conclude that there is thus no benefit from an individual mandate. First, recall that we did report in Table 3 that healthier individuals are more price-sensitive. As such, they might not choose to enroll under a less generous subsidy schedule, meaning an individual mandate could be needed to prevent adverse selection were the subsidy schedule to change. Indeed, Chandra et al. (2011) compare pre- and post-mandate enrollment patterns in Massachusetts and conclude that the mandate was essential in drawing in healthier individuals.

Second, past work (e.g., Currie, 2004) has suggested that enrollment decisions are not merely a function of cost and willingess-to-pay, but of salience and convenience as well, and adverse selection could operate along the latter two margins. For example, being hospitalized might act as a trigger for an individual to enroll in Medicaid or a state exchange; not only does the experience likely make insurance more salient, but hospitals might well have an incentive to facilitate the enrollment process on behalf of the individual so they are reimbursed for his care. Given that contact with hospitals and other medical providers is a function of health, this mechanism might lead sicker individuals to enroll more quickly even if they express no greater demand for insurance. A mandate could increase the salience of health insurance, even among those with limited contact with the health care sector, and thus help equate take-up rates between those in good and poor health.

Finally, our own results suggest that the mandate substantially increases insurance 
coverage. This increase in coverage brings greater access to primary and preventive care, which may have positive spillovers.

\subsection{How would the ACA change the composition of the privately insured?}

The analysis so far has focused on selection within the uninsured population. Now, we compare those we predict will take up private coverage under the ACA to those who already have private insurance. This analysis relates to whether premiums would increase for those already covered by a private plan due to the influx of newly insured individuals via the ACA.

The first column of Table 6 reports summary statistics for insured respondents in the Gallup data who are not covered via Medicaid, Medicare, or veteran's or military insurance. ${ }^{17}$ The second column reports the difference between those who would gain private insurance without a mandate, and the privately insured respondents in the first column. The third column reports this same difference when the mandate is in effect.

The "flow" of the new entrants into private plans are over 2.5 (3.6) years younger than the "stock" of the currently enrolled without (with) a mandate. Both with and without a mandate, there are a greater proportion of smokers in the flow than the stock, though under a mandate those joining exercise more than current enrollees.

With respect to specific conditions and diseases, no clear pattern emerges. A history of high blood pressure, high cholesterol or cancer appear less likely among the new entrants than current enrollees, whereas the reverse is true for heart attacks and asthma. We conclude from these offsetting patterns that, overall, the health of the new entrants is not substantially different than the current enrollees and thus there should be little effect on the premiums of the currently insured through this channel.

\footnotetext{
${ }^{17}$ That is, they are covered by their employer (84 percent) or "other" (16 percent).
} 


\subsection{Welfare analysis and distributional effects of the Affordable Care Act}

Using our willingness-to-pay estimates, it is possible to estimate the implied consumer surpluses resulting from the coverage provisions in the Affordable Care Act. However, these estimates are very crude approximations of the welfare effects of the program. First, they ignore positive externalities from any improvements in health due to increased access to medical care. Second, they only consider the effects on the currently uninsured, whereas many currently insured individuals will see their premiums fall due to ACA subsidies. Third, the currently insured would also benefit from the insurance value of Medicaid expansions and exchange subsidies.

Without a mandate, we define surplus as the difference between willingness to pay and the premium price for all those who do enroll, and zero for those who do not enroll. With a mandate, consumer surplus is also equal to willingness to pay minus the premium price for all those who enroll, but in this case surplus will be negative for all those for whom premium - penalty $<W T P<$ premium. For those who do not enroll, surplus is negative and equal to the amount of the penalty.

Table 7 shows how the level and distribution of the implied consumer surplus varies across the two regimes. The first two columns assume there is no mandate. The average surplus is just under $\$ 1,300$, but among the 64 percent who enroll the surplus is over $\$ 2,000$. The surplus is distributed in a highly progressive manner, with the poorest half of the sample receiving greater benefits than the richer half.

The rest of the table focuses on the case with a mandate. Average surplus falls, which by construction it must, since those who would have taken up without a mandate gain nothing and those who would not have taken up and who are not mandate-exempt are made worse off. ${ }^{18}$ Among those who do not enroll, surplus is bounded above by zero (for those who are mandate-exempt) and negative for anyone who must pay the penalty. The average surplus

\footnotetext{
${ }^{18}$ Of course, this narrow construction does not speak to the desirability of the mandate more generally.
} 
among this group is roughly $-\$ 400$, with the loss to the richer half of households nearly twice that to the poorer half. The last column shows that the average loss to the 35 percent of uninsured individuals made no better off by the policy is roughly $\$ 600$.

One of the largest determinants of whether an individual is made worse off by the mandate is income. On average, those made worse off are in households with income 4.4 times the poverty line, or $\$ 98,000$ for a family of four. As discussed earlier, all else equal, having high income conditional on being uninsured suggests limited preference for health insurance. As these individuals have limited demand but face the steepest penalties, they have the least to gain from the policy.

\section{Conclusion}

We collect new data on uninsured Americans willingness-to-pay for a health insurance plan. As this group is not usually offered health insurance by their employers (the primary providers of health insurance in the US) they are generally excluded from observational data used in the vast majority of past research, which focuses on employer-provided insurance. Yet the preferences of these individuals are key to formulating a policy that could achieve universal coverage.

Instead of relying on observational data, we present uninsured individuals with different premium prices and ask whether they would pay that price to enroll in a health plan equivalent to those offered federal employees. We find elasticities of take-up with respect to price around one, far larger in magnitude than those found in past work. Our results suggest that directly subsidizing the purchase of a private health plan would significantly shrink the uninsured population - for example, more than 60 percent of the uninsured would take up the plan at an annual premium of $\$ 2,000$, and we estimate that 39 million individuals would gain coverage under the specifications of the ACA.

Part of the difference between our result and those in past work is that our sample of uninsured individuals is much poorer than the samples of people offered employer-provided 
insurance used in past papers and the rich and poor may have difference price elasticities (indeed, relatively richer people in our sample have lower elasticities). Moreover, as we focus on plans to subsidize premium prices, we estimate elasticities based on variation around a lower price point than most existing papers, which could lead to different estimated elasticities even if our subjects have the same demand function as subjects in past work.

It may also be that our methodology — which has the advantages of random variation in premium prices and a homogenous insurance product, but some of the disadvantages associated with hypothetical-valuation studies - may also contribute to the difference. While we find little evidence of one common problem with hypothetical valuation (anchoring bias), we realize other concerns still exist. It is worth emphasizing, however, that our experiment differs from contingent valuation studies in important respects. Most importantly, we ask individuals to value a private good with which they should have some experience. By contrast, valuation of hypothetical environmental projects is a much more alien problem. Concerns about hypothetical valuations notwithstanding, our results suggest that extrapolating the effects of premium subsidies for the uninsured from the elasticities generated in past papers could seriously under-estimate the coverage rates these policies could achieve. 


\section{References}

Aizer, A. (2007). Public health insurance, program take-up, and child health. Review of Economics and Statistics, 89 (3), 400-415.

Blumberg, L., Nichols, L. and Banthin, J. (2001). Worker decisions to purchase health insurance. International Journal of Health Care Finance and Economics, 7 (5), 305-325.

Brown, T., Kingsley, D., Petersona, G. L., Flores, N. E., Clarke, A. and BiRJulin, A. (2008). Reliability of individual valuations of public and private goods: Choice consistency, response time, and preference refinement. Journal of Public Economics, 92 (7), 1595-1606.

Card, D. and Shore-Sheppard, L. (2004). Using discontinuous eligibility rules to identify the effects of the federal medicaid expansions on low-income children. Review of Economics and Statistics, 86 (3), 752-766.

Chandra, A., Gruber, J. and McKnight, R. (2011). The importance of the individual mandate evidence from massachusetts. The New England Journal of Medicine, 364, 293-295.

Cheong, P. H., Feeley, T. H. and Servoss, T. (2007). Understanding health inequalities for uninsured americans: A population-wide survey. Journal of Health Communication, 12, 285-3000.

Chernew, M., Frick, K. and McLaughlin, C. (1997). The demand for health insurance by low-income workers: Can reduced premiums achieve full coverage? Health Services Research, 32 (4), 453-470.

Currie, J. (2004). The Take Up of Social Benefits. Working Paper 10488, National Bureau of Economic Research.

— and Gruber, J. (1996). Saving babies: The efficacy and cost of recent changes in the medicaid eligibility of pregnant women. Journal of Political Economy, 104 (6), 12631296.

CutLer, D. (2003). Employee costs and the decline in health insurance coverage. Forum for Health Economics and Policy, 6.

— and Reber, S. (1998). Paying for health insurance: The trade-off between competition and adverse selection. Quarterly Journal of Economics, 113 (2), 433-466.

Daponte, B. O., Sanders, S. and TAYlor, L. (1999). Why do low-income households not use food stamps? evidence from an experiment. Journal of Human Resources, 34 (3), 612-628.

Green, D., Jacowitz, K. E., Kahneman, D. and McFadden, D. (1998). Referendum contingent valuation, anchoring, and willingness to pay for public goods. Resources and Energy Economics, 20 (2), 85 - 116. 
Gruber, J. and Poterba, J. (1994). Tax incentives and the decision to purchase health insurance: Evidence from the self-employed. Quarterly Journal of Economics, 109 (3), 701-733.

- and Washington, E. (2005). Subsidies to employee health insurance premiums and the health insurance market. Journal of Health Economics, 24 (2), 253-276.

Kaiser Family Foundation (2004). Uninsured Workers in America.

Kaiser Family Foundation (2009). Challenges of Providing Health Coverage for Children and Parents in a Recession: A 50 State Update on Eligibility Rules, Enrollment and Renewal Procedures, and Cost-Sharing Practices in Medicaid and SCHIP in 2009.

Klein, K., Glied, S. and Ferry, D. (2005). Entrances and Exits: Health Insurance Churning, 19982000. Tech. Rep. 855, The Commonwealth Fund.

Kwon, S. (2009). Thirty years of national health insurance in south korea: Lessons for achieving universal health care coverage. Health Policy and Planning, 24, 63-71.

Leu, R. E., Rutten, F. F., Brouwer, W., Matter, P. and Rutschi, C. (2009). The Swiss and Dutch Health Insurance Systems: Universal Coverage and Regulated Competitive Insurance Markets. Tech. Rep. 1220, Commonwealth Fund.

Long, S. K., Phadera, L. and Lynch, V. (2010). Massachusetts Health Reform in 2008: Who are the Remaining Uninsured? Tech. rep., Robert Wood Johnson Foundation.

Remler, D. K. and Glied, S. A. (2003). What other programs can teach us: Increasing participation in health insurance programs. Am J Public Health, 93 (1), 67-74.

Rothschild, M. and Stiglitz, J. (1976). Equilibrium in Competitive Insurance Markets: An Essay on the Economics of Imperfect Information. Quarterly Journal of Economics, 90 (4), 629-649.

Sommers, B. D. and Epstein, A. M. (2010). Medicaid expansion the soft underbelly of health care reform? The New England journal of medicine, 363 (22), 2085-2087.

Strombom, B. A., Buchmueller, T. C. and Feldstein, P. J. (2002). Switching costs, price sensitivity and health plan choice. Journal of Health Economics, 21 (1), 89 - 116.

Tversky, A. and Kahneman, D. (1974). Judgment under uncertainty: Heuristics and biases. Science, 185 (4157), 1124-1131. 
Figure 1: Take-up rates by premium price and implied arc elasticities

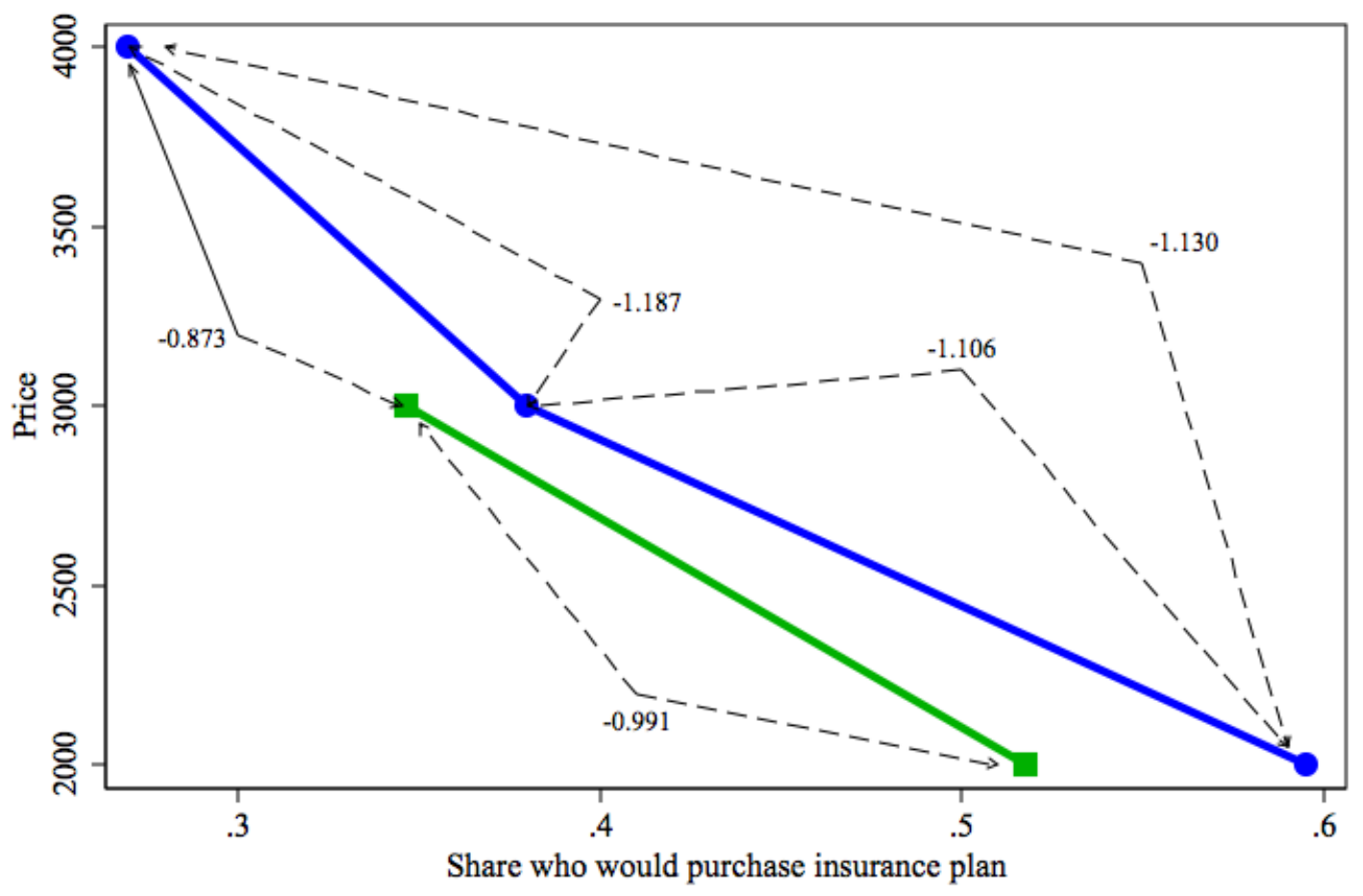

$\longrightarrow$ Questionnaire A $\longrightarrow$ Questionnaire B

Notes: Figure based on data from the Gallup Daily Poll (see text for details). Subjects were randomly given either Questionnaire A (which offers a first price of $\$ 4,000$ and then subsequently $\$ 3,000$ and then $\$ 2,000$ if subject decline at previous price) or Questionnaire B (which initially offers a price of $\$ 3000$ and then $\$ 2,000)$. Arc elasticities not labeled in the Figure are: -0.946 (comparing take-up at $\$ 2,000$ in Questionnaire B and $\$ 4,000$ in Questionnaire A), -0.769 (\$2,000 from $\mathrm{B}$ and $\$ 3,000$ from $\mathrm{A}$ ) and -1.322 ( $\$ 2,000$ from $\mathrm{A}$ and $\$ 3,000$ from $\mathrm{B})$. 
Figure 2: Estimated demand curve for subsidized health plan

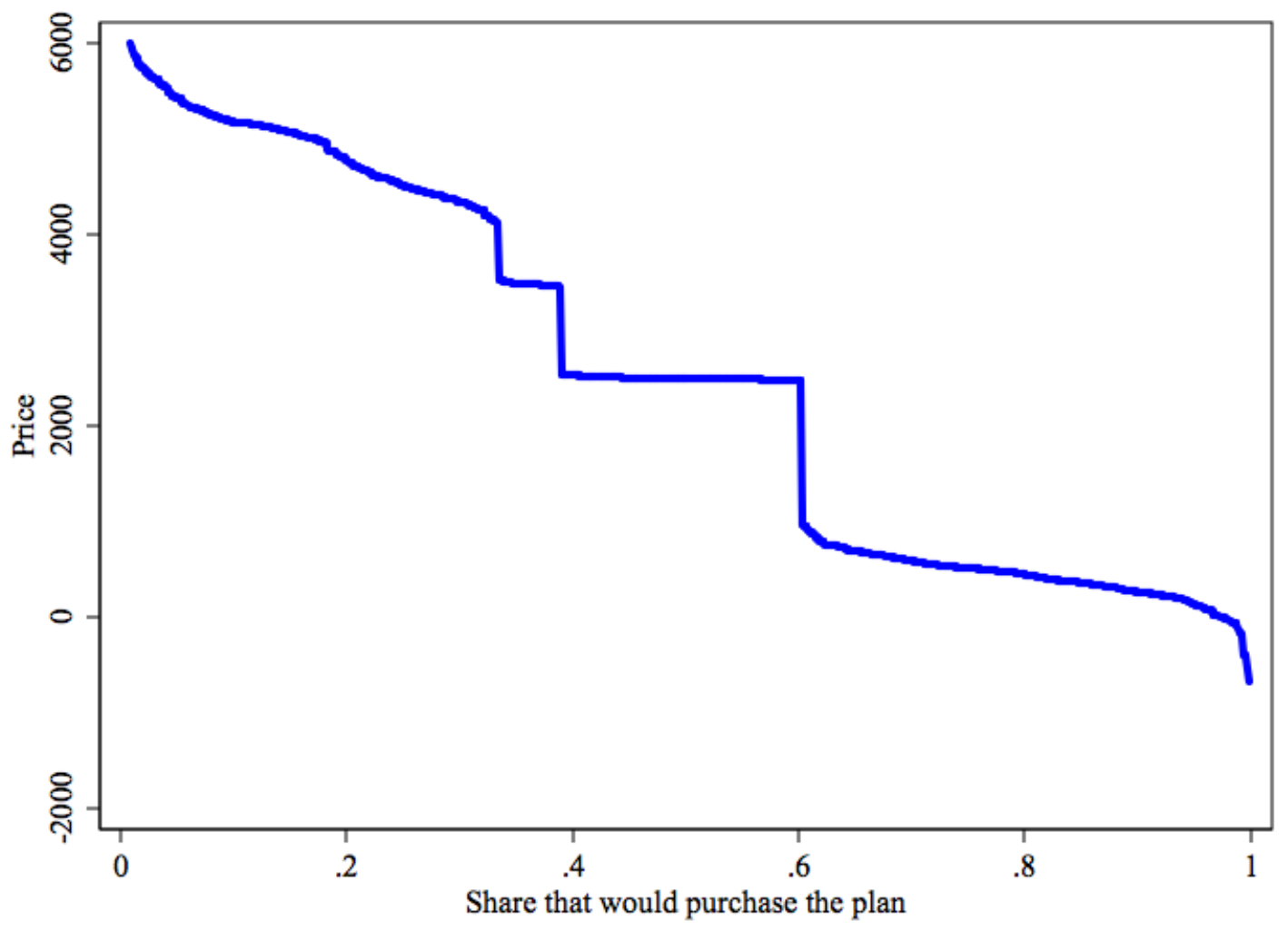

Notes: Estimated reservation prices are plotted on the y-axis and the share with reservation price at or above that value on the x-axis. Reservation prices were estimated using an interval regression of subjects' reported price intervals. See Section 4.3 for details. 
Table 1: Summary statistics by insurance status

\begin{tabular}{|c|c|c|c|c|c|c|}
\hline & \multicolumn{3}{|c|}{ Uninsured } & \multicolumn{3}{|c|}{ Insured } \\
\hline & Obs. & Mean & St. dev. & Obs. & Mean & St. dev. \\
\hline Female & 1213 & 0.461 & 0.499 & 8824 & 0.512 & 0.500 \\
\hline Black & 1067 & 0.115 & 0.319 & 8352 & 0.122 & 0.328 \\
\hline Annual income $\div 1000$ & 984 & 35 & 37.79 & 7203 & 71 & 55.07 \\
\hline Employed & 1213 & 0.640 & 0.480 & 8809 & 0.758 & 0.428 \\
\hline Married & 1204 & 0.353 & 0.478 & 8794 & 0.584 & 0.493 \\
\hline Age & 1213 & 38.39 & 12.84 & 8824 & 42.82 & 12.78 \\
\hline Previously denied insurance & 1182 & 0.139 & 0.346 & 1163 & 0.0633 & 0.244 \\
\hline Body mass index & 1122 & 27.61 & 6.043 & 8518 & 27.27 & 5.910 \\
\hline Days sick last month & 1195 & 3.535 & 8.312 & 8775 & 2.835 & 7.351 \\
\hline Smoker & 1213 & 0.352 & 0.478 & 8819 & 0.206 & 0.405 \\
\hline Days exercised last week & 1197 & 3.156 & 2.649 & 8802 & 2.929 & 2.406 \\
\hline \multicolumn{7}{|l|}{ Ever diagnosed with... } \\
\hline High blood pressure & 1208 & 0.185 & 0.388 & 8800 & 0.240 & 0.427 \\
\hline High cholesterol & 1208 & 0.160 & 0.367 & 8789 & 0.232 & 0.422 \\
\hline Diabetes & 1211 & 0.0860 & 0.280 & 8804 & 0.0836 & 0.277 \\
\hline Heart attack & 1211 & 0.0317 & 0.175 & 8802 & 0.0285 & 0.166 \\
\hline Asthma & 1211 & 0.134 & 0.341 & 8808 & 0.118 & 0.323 \\
\hline Cancer & 1209 & 0.0312 & 0.174 & 8806 & 0.0483 & 0.214 \\
\hline
\end{tabular}

Notes: All data from the Gallup daily poll of adults 18 and over from August 22 to September 8, 2008. We exclude individuals 65 and older, the vast majority of whom would be covered by Medicare. Sample weights provided by Gallup are used. For those with insurance, the question on previous denials of insurance was only asked the first two days of the survey. 
Table 2: Estimating insurance take-up as a function of premium price

\begin{tabular}{|c|c|c|c|c|c|}
\hline & \multicolumn{5}{|c|}{ Dependent Variable: Would purchase health plan } \\
\hline & $(1)$ & $(2)$ & $(3)$ & $(4)$ & $(5)$ \\
\hline Price & $\begin{array}{c}-0.152^{* * *} \\
{[0.0107]}\end{array}$ & $\begin{array}{c}-0.167^{* * *} \\
{[0.0126]}\end{array}$ & $\begin{array}{c}-0.173^{* * *} \\
{[0.0147]}\end{array}$ & $\begin{array}{c}-0.182^{* * *} \\
{[0.0124]}\end{array}$ & $\begin{array}{c}-0.164^{* * *} \\
{[0.0121]}\end{array}$ \\
\hline Female & & & $\begin{array}{c}-0.0491^{* *} \\
{[0.0204]}\end{array}$ & $\begin{array}{l}-0.0523 \\
{[0.0364]}\end{array}$ & \\
\hline Black & & & $\begin{array}{l}0.156^{* * *} \\
{[0.0338]}\end{array}$ & $\begin{array}{l}0.167^{* * *} \\
{[0.0605]}\end{array}$ & \\
\hline Asian & & & $\begin{array}{l}0.178^{* *} \\
{[0.0892]}\end{array}$ & $\begin{array}{c}0.189 \\
{[0.151]}\end{array}$ & \\
\hline Hispanic & & & $\begin{array}{l}-0.0607^{*} \\
{[0.0314]}\end{array}$ & $\begin{array}{l}-0.0638 \\
{[0.0622]}\end{array}$ & \\
\hline Age & & & $\begin{array}{c}0.000129 \\
{[0.000816]}\end{array}$ & $\begin{array}{l}0.000121 \\
{[0.00139]}\end{array}$ & \\
\hline Log of income & & & $\begin{array}{l}0.0318^{* * *} \\
{[0.00570]}\end{array}$ & $\begin{array}{c}0.0341^{* * *} \\
{[0.0117]}\end{array}$ & \\
\hline $\begin{array}{l}\text { Randomized to } \\
\text { Questionnaire A }\end{array}$ & & & $\begin{array}{c}0.0159 \\
{[0.0217]}\end{array}$ & $\begin{array}{c}0.0144 \\
{[0.0363]}\end{array}$ & \\
\hline Estimation method & OLS & OLS & OLS & Probit & OLS, fix. eff. \\
\hline Sample & All & $\begin{array}{l}\text { No missing } \\
\text { controls }\end{array}$ & $\begin{array}{l}\text { No missing } \\
\text { controls }\end{array}$ & $\begin{array}{c}\text { No missing } \\
\text { controls }\end{array}$ & All \\
\hline Observations & 2,975 & 2,202 & 2,202 & 2,202 & 2,975 \\
\hline
\end{tabular}

Notes: See Table 1 for information on data and sampling. Each observation is a person-price, where price takes on values of $\{\$ 2,000, \$ 3,000, \$ 4,000\}$ if the respondent received questionnaire A or $\{\$ 2,000, \$ 3,000\}$ if the respondent received questionnaire B. All regressions are weighted by sample weights provided by Gallup, though sample weights are multiplied by $\frac{2}{3}$ for those in Questionnaire A so that they do not make a larger contribution to the estimate merely because they have three price points, though results are unchanged if the original Gallup sample weights are used. 
Table 3: Estimates of the elasticity of take-up with respect to premium price

\begin{tabular}{lcc}
\hline Subsample & Elasticity & Observations \\
\hline All & -1.074 & 2975 \\
Female & -1.110 & 1293 \\
Over age fifty & -0.911 & 956 \\
Married & -0.992 & 1071 \\
Top income quartile & & 138 \\
Bottom three quartiles & -0.757 & 2311 \\
Employed & -1.107 & 1945 \\
Obese (BMI greater than 30) & & \\
Smoker & -1.072 & 745
\end{tabular}

Notes: See Tables 1 and 2. Elasticities are based on the fixed-effects regression in col. (5) of Table 2, estimated separately for each subsample. "Top income quartile" is based on being above the $75^{\text {th }}$ percentile in household income in our data $(\$ 54,000)$ and "has a health problem" is defined as answering "yes" to the question: "Do you have any health problems that prevent you from doing any of the things people your age normally do?" Observations are counted at the person-price level. 
Table 4: Enrollment estimates under the Affordable Care Act under various assumptions regarding Medicaid enrollment

\begin{tabular}{|c|c|c|c|c|c|c|}
\hline \multirow[b]{3}{*}{ Medicaid assumption } & \multicolumn{3}{|c|}{ Without "mandate" } & \multicolumn{3}{|c|}{ With "mandate" } \\
\hline & \multirow[b]{2}{*}{ Take-up rate } & \multicolumn{2}{|c|}{ Number (millions) } & \multirow{2}{*}{ Take-up rate } & \multicolumn{2}{|c|}{ Number (millions) } \\
\hline & & Adults & Total & & Adults & Total \\
\hline Enroll if $W T P>0$ & 0.643 & 27.5 & 32.8 & 0.770 & 33.0 & 39.3 \\
\hline $85 \%$ take up & 0.615 & 26.3 & 31.4 & 0.763 & 32.7 & 38.9 \\
\hline $50 \%$ take up & 0.477 & 20.4 & 24.3 & 0.722 & 30.9 & 36.8 \\
\hline Excl. Medicaid eligibles & 0.463 & 10.3 & 12.3 & 0.639 & 14.3 & 17.0 \\
\hline $\begin{array}{l}\text { Total obs. } \\
\text {-Ex. Medicaid }\end{array}$ & $\begin{array}{l}816 \\
535\end{array}$ & & & & & \\
\hline
\end{tabular}

Notes: Estimates based on willingess-to-pay results estimated from the Gallup data in Section 4.3. As subsidies are based on an individual's income, we can only estimate the effect of ACA provisions on the 816 observations for whom we have both a willingness-to-pay estimate and a valid response to the household income question. The first row assumes any enrollee for whom $W T P>$ premium - penalty will take-up coverage, and thus assumes that any Medicaid-eligible individual with positive $W T P$ will enroll, as premiums are equal to zero for this group. The second and third column treat Medicaid eligibles differently, assuming that, respectively, only 85 and 50 percent will enroll. The second and fifth columns merely multiply the first column and fourth column, respectively, by the CBO's estimate of the total number of uninsured in 2014 without the ACA (51 million) and the adult share of the uninsured in 2009 (.839). The estimated totals in the third and sixth column merely scale the numbers in, respectively, the first and fourth column by the entire 51 million and thus assume that children have the same take-up rates as adults. The fourth row replicates the first row, but only for the 535 observations with valid willingness-to-pay and income measure who are also above 133 percent of the poverty line and thus ineligible for Medicaid. 
Table 5: Characteristics of those predicted to take up coverage or remain uncovered under $\underline{\mathrm{ACA}}$

Without mandate $\quad$ With mandate

Covered Uncov. Diff. Covered Uncov. Diff.

General health variables

Has a health problem

Body mass index

Days sick last month

Smoker

Days exercised last week

Previously denied insurance

Age

Ever diagnosed with...

High blood pressure

High cholesterol

Cancer

Heart attack

Diabetes

Asthma

Demographic variables

Female

Black

Hispanic

Annual income $\div 1000$

Employed

Married
0.25

28.1

3.99

0.37

3.12

0.15

40.1
0.20

27.2

3.45

0.44

3.37

0.11

37.6
0.047

0.93

0.53

$-0.072$

$-0.25$

0.044

2.58
0.24

28.0

4.02

0.38

3.14

0.14

39.4
0.21

27.2

3.04

0.45

3.44

0.12

38.6
0.032

0.78

0.98

$-0.077$

$-0.30$

0.020

0.81

Share enrolling $\quad 0.64 \quad 0.77$

Notes: The sample in this table are all 816 Gallup respondents who report being currently uninsured and have both an estimated willingness-to-pay value from Section 4.3 and non-missing household income information. "Covered" refers those who are predicted to take-up either Medicaid or exchange coverage under ACA, and "Uncovered" refers to the rest of the currently uninsured. We assume an individual will take-up coverage whenever $W T P>$ premium - penalty, so these estimates correspond to the first row of Table $4 .{ }^{*} p<0.1^{* *} p<0.05$ 
Table 6: Comparing those gaining private coverage under ACA to current private enrollees

\begin{tabular}{lccc}
\hline & & \multicolumn{2}{l}{ Difference: New versus current enrollees } \\
\cline { 4 - 4 } & & & \\
& Current enrollees & No mandate & Mandate \\
\hline & & & \\
General health variables & 42.9 & $-2.57^{* *}$ & $-3.64^{* *}$ \\
Age & 0.13 & 0.030 & $0.039^{* *}$ \\
Has a health problem & 27.1 & 0.47 & 0.40 \\
Body mass index & 1.83 & 0.51 & $0.87^{* *}$ \\
Days sick last month & 0.18 & $0.13^{* *}$ & $0.15^{* *}$ \\
Smoker & 2.92 & 0.18 & $0.27^{* *}$ \\
Days exercised last week & 0.061 & $0.087^{* *}$ & $0.073^{* *}$ \\
Previously denied insurance & & & \\
& & & -0.025 \\
Ever diagnosed with... & 0.22 & $-0.045^{*}$ & $-0.087^{* *}$ \\
High blood pressure & 0.22 & $-0.081^{* *}$ & $-0.017^{*}$ \\
High cholesterol & 0.044 & -0.016 & $0.015^{* *}$ \\
Cancer & 0.019 & $0.016^{* *}$ & 0.013 \\
Heart attack & 0.068 & -0.0055 & 0.0017 \\
Diabetes & 0.10 & $0.037^{* *}$ & 354 \\
Asthma & 7726 & 264 & \\
\hline Observations & & & \\
\hline
\end{tabular}

Notes: The first column includes all those in the Gallup survey who report having health insurance, but excludes those who are on Medicaid or Medicare or on veteran's or military insurance (leaving employer and "other" as the source of insurance). The second column reports the difference between: 1) all the uninsured in the Gallup survey who are predicted to take up coverage under ACA without a mandate but who are over 133 percent of the poverty line and thus ineligible for Medicaid; and 2) the individuals in the first column. The third column is identical to the second but assumes the ACA mandate is in place. ${ }^{*} p<0.1^{* *} p<0.05$ 
Table 7: Estimates of consumer surplus under the Affordable Care Act

\begin{tabular}{|c|c|c|c|c|c|c|c|}
\hline & & & \multicolumn{5}{|c|}{ With mandate } \\
\hline & \multicolumn{2}{|c|}{ Without mandate } & \multirow[b]{2}{*}{ All } & \multicolumn{2}{|c|}{ Enrolled/Mcaid } & \multicolumn{2}{|c|}{ Surplus > 0} \\
\hline & All & Enrolled/Mcaid & & Yes & No & Yes & No \\
\hline Average surplus & 1291 & 2007 & 1085 & 1526 & -396 & 2007 & -580 \\
\hline Avg., low income & 1633 & 2180 & 1555 & 1897 & -279 & 2180 & -311 \\
\hline Avg., high income & 637 & 1445 & 184 & 579 & -491 & 1445 & -810 \\
\hline Share of total & & 0.643 & & 0.770 & 0.230 & 0.643 & 0.357 \\
\hline \multicolumn{8}{|c|}{$\begin{array}{l}\text { Notes: Consumer surplus is equal to willingess to pay minus premium price for all those who } \\
\text { enroll in a plan. Enrollment is assumed whenever } W T P>\text { premium-penalty, as in the first row } \\
\text { of Table } 4 \text {. For those who do not enroll, consumer surplus is set to zero under the no-mandate } \\
\text { assumption. Under a mandate, it remains at zero for those who are mandate-exempt, and equal } \\
\text { to - penalty for those not exempt. "High" and "low income" refer, respectively, to those above }\end{array}$} \\
\hline
\end{tabular}


Appendix Table 1: Characteristics of those predicted to take up coverage or remain uncovered under ACA, excluding Medicaid eligibles

\begin{tabular}{|c|c|c|c|c|c|c|}
\hline & \multicolumn{3}{|c|}{ Without mandate } & \multicolumn{3}{|c|}{ With mandate } \\
\hline & Covered & Uncov. & Diff. & Covered & Uncov. & Diff. \\
\hline \multicolumn{7}{|l|}{ General health variables } \\
\hline Has a health problem & 0.16 & 0.19 & -0.032 & 0.17 & 0.19 & -0.023 \\
\hline Body mass index & 27.6 & 27.4 & 0.20 & 27.5 & 27.4 & 0.12 \\
\hline Days sick last month & 2.34 & 3.17 & -0.82 & 2.70 & 2.94 & -0.23 \\
\hline Smoker & 0.31 & 0.42 & $-0.11^{* *}$ & 0.33 & 0.44 & $-0.10^{*}$ \\
\hline Days exercised last week & 3.10 & 3.47 & -0.37 & 3.19 & 3.49 & -0.30 \\
\hline Previously denied insurance & 0.15 & 0.11 & 0.036 & 0.13 & 0.12 & 0.016 \\
\hline Age & 40.3 & 37.9 & 2.44 & 39.3 & 38.6 & 0.67 \\
\hline
\end{tabular}

Ever diagnosed with...

High blood pressure

$\begin{array}{cccccc}0.17 & 0.15 & 0.020 & 0.19 & 0.11 & 0.084^{* *} \\ 0.14 & 0.13 & 0.0095 & 0.13 & 0.13 & -0.0029 \\ 0.029 & 0.033 & -0.0046 & 0.028 & 0.037 & -0.0099 \\ 0.035 & 0.027 & 0.0085 & 0.034 & 0.025 & 0.0090 \\ 0.063 & 0.083 & -0.020 & 0.081 & 0.061 & 0.020 \\ 0.14 & 0.073 & 0.066^{* *} & 0.10 & 0.10 & 0.00095\end{array}$

High cholesterol

Cancer

Heart attack

0.16

0.19

$-0.032$

.023

Diabetes

Asthma

0.10

0.00095

Demographic variables

\begin{tabular}{lcccccc} 
Female & 0.42 & 0.35 & 0.070 & 0.39 & 0.37 & 0.027 \\
Black & 0.12 & 0.060 & $0.061^{*}$ & 0.10 & 0.063 & 0.040 \\
Hispanic & 0.092 & 0.050 & 0.042 & 0.074 & 0.062 & 0.012 \\
Annual income $\div 1000$ & 52.9 & 55.9 & -2.97 & 59.9 & 45.1 & $14.8^{* *}$ \\
Employed & 0.77 & 0.80 & -0.026 & 0.77 & 0.81 & -0.038 \\
Married & 0.34 & 0.32 & 0.025 & 0.31 & 0.36 & -0.052 \\
\hline Share enrolling & 0.46 & \multicolumn{5}{c}{0.64} \\
\hline
\end{tabular}

Notes: See Table 5. The sample in this table are all 535 Gallup respondents who report being currently uninsured, have both an estimated willingness-to-pay value from Section 4.3 and nonmissing household income information, and are at at least 133 percent of the poverty line and thus ineligible for Medicaid. 


\section{Survey questions}

\section{Questionnaire A}

- If you could get a health insurance policy for yourself that is as good as the one that members of Congress have, given your current financial situation, would you buy it for $\$ 4,000$ a year, which works out to $\$ 333$ per month?

- If you could get that health insurance plan for $\$ 3,000$ a year, which works out to $\$ 250$ per month, would you buy it?

- If you could get that health insurance plan for $\$ 2,000$ a year, which works out to $\$ 167$ per month, would you buy it?

\section{Questionnaire B}

- If you could get a health insurance policy for yourself that is as good as the one that members of Congress have, given your current financial situation, would you buy it for $\$ 3,000$ a year, which works out to $\$ 250$ per month?

- If you could get that health insurance plan for $\$ 2,000$ a year, which works out to $\$ 167$ per month, would you buy it? 